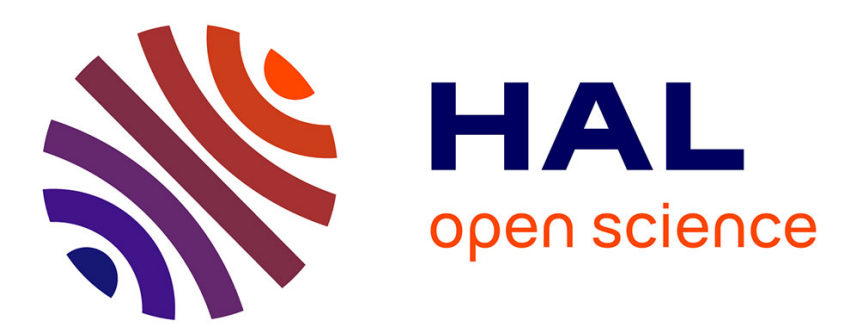

\title{
Analytical Computation of the Magnetic Field Distribution in a Magnetic Gear
}

Thierry Lubin, Smail Mezani, Abderrezak Rezzoug

\section{To cite this version:}

Thierry Lubin, Smail Mezani, Abderrezak Rezzoug. Analytical Computation of the Magnetic Field Distribution in a Magnetic Gear. IEEE Transactions on Magnetics, 2010, 46 (7), pp.2611-2621. 10.1109/TMAG.2010.2044187 . hal-00558537

\section{HAL Id: hal-00558537 https://hal.science/hal-00558537}

Submitted on 13 Nov 2011

HAL is a multi-disciplinary open access archive for the deposit and dissemination of scientific research documents, whether they are published or not. The documents may come from teaching and research institutions in France or abroad, or from public or private research centers.
L'archive ouverte pluridisciplinaire HAL, est destinée au dépôt et à la diffusion de documents scientifiques de niveau recherche, publiés ou non, émanant des établissements d'enseignement et de recherche français ou étrangers, des laboratoires publics ou privés. 


\title{
Analytical Computation of the Magnetic Field Distribution in a Magnetic Gear
}

\author{
Thierry Lubin, Smail Mezani, and Abderrezak Rezzoug. \\ Groupe de Recherche en Electrotechnique et Electronique de Nancy, \\ University Henri Poincaré, Nancy, FRANCE
}

\begin{abstract}
In this paper, an analytical computation of the magnetic field distribution in a magnetic gear is proposed. The analytical method is based on the resolution of Laplace's and Poisson's equations (by the separation of variables technique) for each sub-domain, i.e. magnets, air-gap and slots. The global solution is obtained using boundary and continuity conditions. The analytical model developed in this paper can be used as a tool for design optimization of a magnetic gear. Magnetic field distributions and electromagnetic torque computed with the proposed analytical method are compared with those obtained from finite element analyses.
\end{abstract}

Index Terms - Analytical solution, magnetic gear, magnetic field, electromagnetic torque.

\section{INTRODUCTION}

$\mathrm{M}$ AGNETIC gears offer substantial advantages compared to mechanical gears such as reduced maintenance, improved reliability, minimum acoustic noise and inherent overload protection. Physical and hermetic isolation between input and output shafts are also specific to such contactless torque transmission devices [1]-[5]. It has been shown that a transmitted torque density of $100 \mathrm{kNm} / \mathrm{m}^{3}$ can be obtained which is comparable with that of mechanical gears. Recently, magnetic gear has been integrated into PM motors to obtain the so called "pseudo-direct" drives that result in high-torque density electrical machines [6]. The later actuators are suitable for high torque low speed application like electric vehicles [7] or wind power generation [8].

An accurate knowledge of the air-gap magnetic field distribution is necessary for predicting the performance of the magnetic gear. The air-gap magnetic field can be evaluated by analytical or semi-analytical methods or by numerical techniques like finite elements. Finite elements give accurate results considering geometric details and nonlinearity of magnetic materials. However, this method is computer time consuming and poorly flexible for the first step of design stage of a magnetic gear. Analytical methods are useful tools for first evaluation of magnetic gear performances and for design optimization since continuous derivatives issued from the analytical solution are of great importance in most optimization methods.

As shown in Fig. 1, a magnetic gear contains a ring of $Q$ ferromagnetic pole-pieces which are difficult to handle (open slots on two sides) in the analytical prediction of the air-gap magnetic field. Analytical approaches for air-gap magnetic field computation in slotted machines can be found in the literature [9]-[14]. However, the publications focus essentially on the determination of cogging torque in permanent magnet motors.

Digital Object Identifier inserted by IEEE
The aim of this paper is to propose an exact analytical solution of the magnetic field distribution in a magnetic gear. The Laplace and Poisson's equations are solved in each subdomain (air-gap, magnet and slots) and the solution is obtained using boundary and interface conditions.

The paper is organized as follows. The problem description and the assumptions of the model are presented in section II. Section III describes the analytical method for magnetic field calculation in the air-gap, permanent magnets and in the slot sub-domains. The analytical results are then verified with finite-element method in section IV and section V.

\section{PROBLEM DESCRIPTION AND ASSUMPTIONS}

Schematic representation of the studied magnetic gear is shown in Fig. 1. It consists of a $p_{i}$ pole-pairs inner rotor, a $p_{o}$ pole-pairs outer rotor and $Q$ ferromagnetic pole-pieces.

Principle of operation of the magnetic gear is the modulation of magnetic field created by the $p_{i}$ pole-pairs PMs rotor (prime mover) by the $\mathrm{Q}$ pole pieces. The obtained field interacts with the $p_{o}$ pole-pairs PMs rotor to transmit torque to the load (outer rotor or pole pieces) at a different speed. The combination $Q=p_{i}+p_{\mathrm{o}}$ results in the highest torque transmission capability of the gear. If the pole pieces are kept stationary, the resulting gear ratio is $p_{o} / p_{i}[1]$.

The geometrical parameters are:

- for the inner rotor, the radius of the yoke $R_{1}$ and the outer radius of the PMs $R_{2}$;

- for the ring, the inner and outer radii of the slots $R_{3}, R_{4}$ respectively;

- and for the outer rotor, the inner radius of PMs $R_{5}$ and the inner radius of the yoke $\mathrm{R}_{6}$.

The slot opening angle is $\beta$. The angular position of the $i$-th slot is defined as

$\theta_{i}=-\frac{\beta}{2}+\frac{2 i \pi}{Q}+\theta_{0} \quad$ with $\quad 1 \leq i \leq Q$

where $\theta_{0}$ is the initial angular position of the pole-pieces ring. 


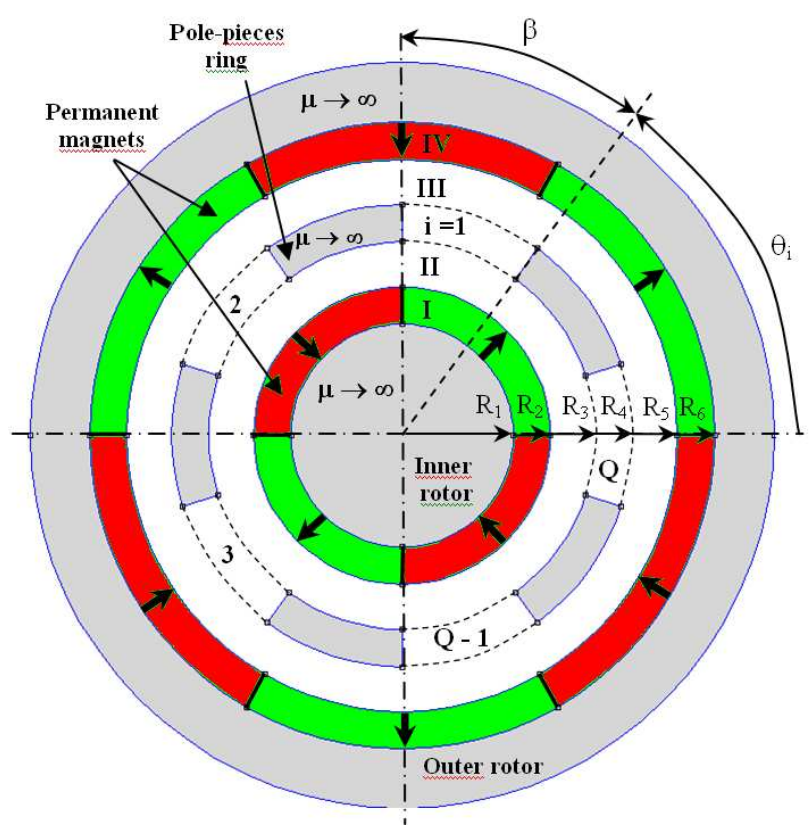

Fig. 1. Geometry of the studied magnetic gear $\left(Q=5, \theta_{0}=0, \mathrm{p}_{\mathrm{i}}=2, \mathrm{p}_{\mathrm{o}}=3\right)$.

The following assumptions are adopted:

- End effects are neglected.

- The permeability of the iron is infinite (the magnetic field in the iron vanishes).

- The relative recoil permeability of the magnets is $\mu_{r}=1$.

As shown in Fig.1, the whole domain is divided into five sub-domains: the inner and outer air-gap sub-domains (regions II and III), the inner and outer PMs sub-domains (regions I and IV) and the $Q$ slots sub-domains (regions i). The $i$-th slot subdomain shape is shown in Fig. 2. The sub-domains I, II, III and IV have annular shapes.

A magnetic vector potential formulation is used in $2 \mathrm{D}$ polar coordinates to describe the problem. According to the adopted assumptions, the magnetic vector potential has only one component along the z-direction and only depends on the $r$ and $\theta$ coordinates. The notations used in the paper are

$$
\begin{array}{ll}
\boldsymbol{A}_{I}=A_{I}(r, \theta) \cdot \boldsymbol{e}_{z} & \text { for the inner PMs sub-domain } \\
\boldsymbol{A}_{I I}=A_{I I}(r, \theta) \cdot \boldsymbol{e}_{z} & \text { for the inner air-gap sub-domain } \\
\boldsymbol{A}_{\boldsymbol{i}}=A_{i}(r, \theta) \cdot \boldsymbol{e}_{z} & \text { for the } i \text {-th slot sub-domain } \\
\boldsymbol{A}_{I I I}=A_{I I I}(r, \theta) \cdot \boldsymbol{e}_{z} & \text { for the outer air-gap sub-domain } \\
\boldsymbol{A}_{I V}=A_{I V}(r, \theta) \cdot \boldsymbol{e}_{z} & \text { for the outer PMs sub-domain }
\end{array}
$$

\section{ANALYTICAL MODEL}

The solution of any partial differential equation (PDE) depends on the domain in which the solution is to be valid as well as the boundary conditions that the solution must satisfy. By using separation of variables, we now consider the solution of Laplace's equation for the slots and the air-gap sub-domains and the Poisson's equation for the PMs sub-domains. For the sake of clarity and simplicity of the general solutions in the different sub-domains, we adopt the following notations

$$
\begin{aligned}
& P_{w}(u, v)=\left(\frac{u}{v}\right)^{w}+\left(\frac{v}{u}\right)^{w} \\
& E_{w}(u, v)=\left(\frac{u}{v}\right)^{w}-\left(\frac{v}{u}\right)^{w}
\end{aligned}
$$

\section{A. General Solution of Laplace's equation in the $i$-th slot sub-domain (region i)}

The $i$-th slot sub-domain and the associated boundary conditions are shown in Fig. 2. We have to solve the Laplace's equation in a domain of inner radius $R_{3}$ and outer radius $R_{4}$ delimited by the angles $\theta_{i}$ and $\theta_{i}+\beta$

$$
\frac{\partial^{2} A_{i}}{\partial r^{2}}+\frac{1}{r} \frac{\partial A_{i}}{\partial r}+\frac{1}{r^{2}} \frac{\partial^{2} A_{i}}{\partial \theta^{2}}=0 \text { for }\left\{\begin{array}{l}
R_{3} \leq r \leq R_{4} \\
\theta_{i} \leq \theta \leq \theta_{i}+\beta
\end{array}\right.
$$

The boundary conditions for the $i$-th slot domain are (the tangential component of the magnetic field at the sides of the slot are null)

$$
\left.\frac{\partial A_{i}}{\partial \theta}\right|_{\theta=\theta_{i}}=0 \quad \text { and }\left.\quad \frac{\partial A_{i}}{\partial \theta}\right|_{\theta=\theta_{i}+\beta}=0
$$

The continuity of the normal component of the flux density between the $i$-th slot and the air-gap sub-domains leads to

$$
\begin{aligned}
& A_{i}\left(R_{3}, \theta\right)=A_{I I}\left(R_{3}, \theta\right) \\
& A_{i}\left(R_{4}, \theta\right)=A_{I I I}\left(R_{4}, \theta\right)
\end{aligned}
$$

The general solution of (4) can be found by using the method of the separation of variables, the solution can be written as [14]

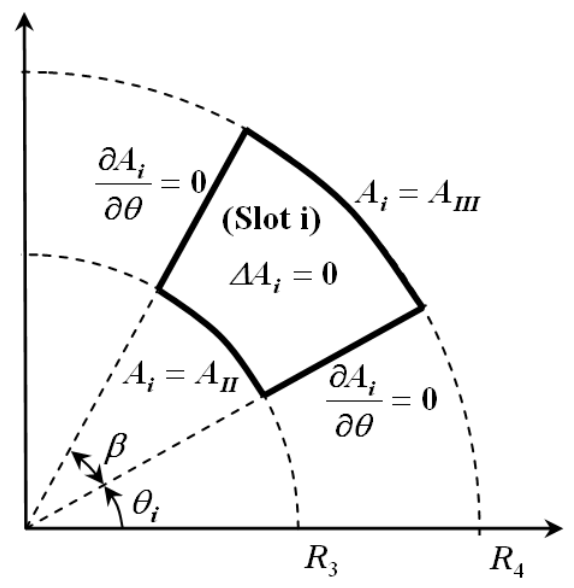

Fig. 2. $i$-th slot sub-domain with its boundary conditions 
$A_{i}(r, \theta)=A_{0}^{i}+B_{0}^{i} \ln r$

$+\sum_{k=1}^{\infty}\left(A_{k}^{i} r^{-\frac{k \pi}{\beta}}+B_{k}^{i} r^{\frac{k \pi}{\beta}}\right) \cdot \cos \left(\frac{k \pi}{\beta}\left(\theta-\theta_{i}\right)\right)$

where $A_{0}^{i}, B_{0}^{i}, A_{k}^{i}$ and $B_{k}^{i}$ are arbitrary constants

Considering the continuity conditions (6) and (7), the general solution of the magnetic vector potential in the $i$-th slot domain is rewritten as

$$
\begin{aligned}
& A_{i}(r, \theta)=A_{0}^{i}+B_{0}^{i} \ln r \\
& +\sum_{k=1}^{\infty}\left(A_{k}^{i} \frac{E_{k \pi / \beta}\left(r, R_{4}\right)}{E_{k \pi / \beta}\left(R_{3}, R_{4}\right)}-B_{k}^{i} \frac{E_{k \pi / \beta}\left(r, R_{3}\right)}{E_{k \pi / \beta}\left(R_{3}, R_{4}\right)}\right) \cdot \cos \left(\frac{k \pi}{\beta}\left(\theta-\theta_{i}\right)\right)
\end{aligned}
$$

Where $\mathrm{k}$ is a positive integer, $E_{k \pi / \beta}\left(r, R_{4}\right)$ is defined by (3).

The constants $A_{0}^{i}, B_{0}^{i}, A_{k}^{i}$ and $B_{k}^{i}$ are determined using a Fourier series expansion of the inner and outer air-gap magnetic vector potentials $A_{I I}\left(R_{3}, \theta\right)$ and $A_{I I I}\left(R_{4}, \theta\right)$ over the slot interval $\left[\theta_{i}, \theta_{i}+\beta\right]$.

$$
\begin{aligned}
& A_{0}^{i}+B_{0}^{i} \ln R_{3}=\frac{1}{\beta} \int_{\theta_{i}}^{\theta_{i}+\beta} A_{I I}\left(R_{3}, \theta\right) \cdot d \theta \\
& A_{0}^{i}+B_{0}^{i} \ln R_{4}=\frac{1}{\beta} \int_{\theta_{i}}^{\theta_{i}+\beta} A_{I I I}\left(R_{4}, \theta\right) \cdot d \theta \\
& A_{k}^{i}=\frac{2}{\beta} \int_{\theta_{i}}^{\theta_{i}+\beta} A_{I I}\left(R_{3}, \theta\right) \cdot \cos \left(\frac{k \pi}{\beta}\left(\theta-\theta_{i}\right)\right) \cdot d \theta \\
& B_{k}^{i}=\frac{2}{\beta} \int_{\theta_{i}}^{\theta_{i}+\beta} A_{I I I}\left(R_{4}, \theta\right) \cdot \cos \left(\frac{k \pi}{\beta}\left(\theta-\theta_{i}\right)\right) \cdot d \theta
\end{aligned}
$$

The expressions for the coefficients $A_{0}^{i}, B_{0}^{i}, A_{k}^{i}$ and $B_{k}^{i}$ are given in the appendix.

\section{B. General solution of Laplace's equation in the air-gap sub-domains}

\section{1) Inner air-gap sub-domain (region II)}

The inner air-gap sub-domain and the associated boundary conditions are shown in Fig. 3. The problem to solve is

$$
\frac{\partial^{2} A_{I I}}{\partial r^{2}}+\frac{1}{r} \frac{\partial A_{I I}}{\partial r}+\frac{1}{r^{2}} \frac{\partial^{2} A_{I I}}{\partial \theta^{2}}=0 \quad \text { for } \quad\left\{\begin{array}{l}
R_{2} \leq r \leq R_{3} \\
0 \leq \theta \leq 2 \pi
\end{array}\right.
$$

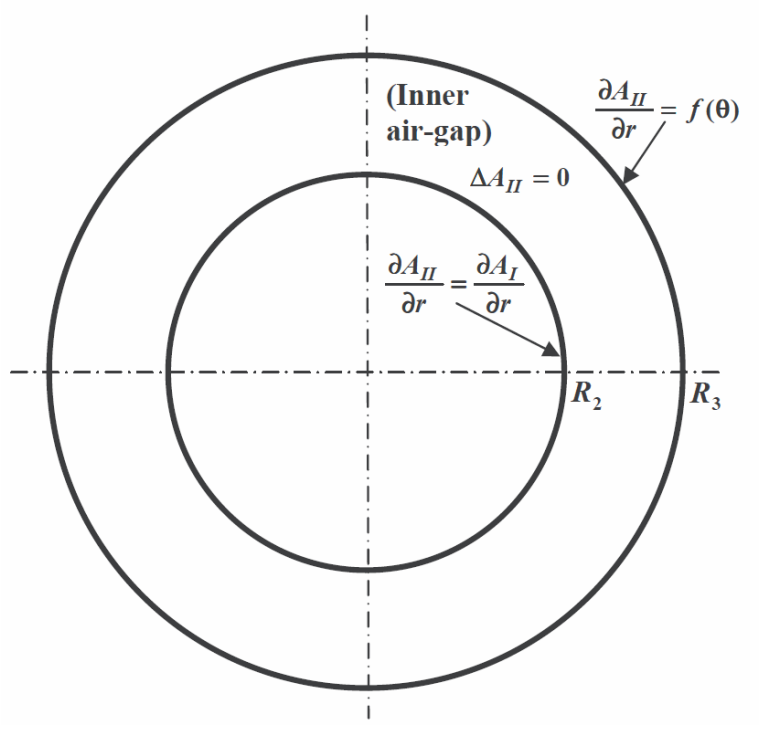

Fig. 3. Inner air-gap sub-domain (region II) with its boundary conditions.

The continuity of the tangential component of the magnetic field at $r=R_{2}$ leads to:

$\left.\frac{\partial A_{I I}}{\partial r}\right|_{r=R_{2}}=\left.\frac{\partial A_{I}}{\partial r}\right|_{r=R_{2}}$

The boundary condition at the radius $r=R_{3}$ is more difficult to handle because of the existence of the slots as shown in Fig. 1. Considering the continuity of the tangential magnetic field at the interface between the slots and the air-gap and considering that the tangential magnetic field is equal to zero elsewhere (infinite permeability of the ferromagnetic pieces), the boundary condition at $r=R_{3}$ can be written as

$\left.\frac{\partial A_{I I}}{\partial r}\right|_{r=R_{3}}=f(\theta)$

with

$$
f(\theta)= \begin{cases}\left.\frac{\partial A_{i}}{\partial r}\right|_{r=R_{3}} & \forall \theta \in\left[\theta_{i}, \theta_{i}+\beta\right] \\ 0 & \text { elsewhere }\end{cases}
$$

where $A_{i}(r, \theta)$ is the magnetic vector potential in the $i$-th slot given by (9). The distribution of $f(\theta)$ along the air-gap domain interval $[0,2 \pi]$ is schematically shown in Fig. 4.

The general solution of (14) is well known [15] (periodic Sturm-Liouville problem in an annulus). By taking into account the boundary conditions (15) and (16), the general solution of the magnetic vector potential in the inner air-gap can be written as 


$$
\begin{aligned}
& A_{I I}(r, \theta)=A_{0}^{I I} \\
& +\sum_{n=1}^{\infty}\left(A_{n}^{I I} \frac{R_{2}}{n} \frac{P_{n}\left(r, R_{3}\right)}{E_{n}\left(R_{2}, R_{3}\right)}+B_{n}^{I I} \frac{R_{3}}{n} \frac{P_{n}\left(r, R_{2}\right)}{E_{n}\left(R_{3}, R_{2}\right)}\right) \cos (n \theta) \\
& +\sum_{n=1}^{\infty}\left(C_{n}^{I I} \frac{R_{2}}{n} \frac{P_{n}\left(r, R_{3}\right)}{E_{n}\left(R_{2}, R_{3}\right)}+D_{n}^{I I} \frac{R_{3}}{n} \frac{P_{n}\left(r, R_{2}\right)}{E_{n}\left(R_{3}, R_{2}\right)}\right) \sin (n \theta)
\end{aligned}
$$

where $n$ is a positive integer, $P_{n}\left(r, R_{3}\right)$ and $E_{n}\left(R_{2}, R_{3}\right)$ are defined by (2) and (3). The coefficients $A_{n}^{I I}, B_{n}^{I I}, C_{n}^{I I}$ and $D_{n}^{I I}$ are determined using a Fourier series expansions of $\left.\frac{\partial A_{I}}{\partial r}\right|_{R_{2}}$ and $f(\theta)$ over the air-gap interval $[0,2 \pi]$

$$
\begin{aligned}
& A_{n}^{I I}=\left.\frac{2}{2 \pi} \int_{0}^{2 \pi} \frac{\partial A_{I}}{\partial r}\right|_{R_{2}} \cdot \cos (n \theta) \cdot d \theta \\
& B_{n}^{I I}=\frac{2}{2 \pi} \int_{0}^{2 \pi} f(\theta) \cdot \cos (n \theta) \cdot d \theta \\
& C_{n}^{I I}=\left.\frac{2}{2 \pi} \int_{0}^{2 \pi} \frac{\partial A_{I}}{\partial r}\right|_{R_{2}} \cdot \sin (n \theta) \cdot d \theta \\
& D_{n}^{I I}=\frac{2}{2 \pi} \int_{0}^{2 \pi} f(\theta) \cdot \sin (n \theta) \cdot d \theta
\end{aligned}
$$

The expressions for the coefficients $A_{n}^{I I}, B_{n}^{I I}, C_{n}^{I I}$ and $D_{n}^{I I}$ are given in the appendix.

The Neumann problem (14), (15) and (16) can have a solution only if [15] :

$$
\left.\int_{0}^{2 \pi} \frac{\partial A_{I}}{\partial r}\right|_{R_{2}} \cdot d \theta=\int_{0}^{2 \pi} f(\theta) \cdot d \theta
$$

The treatment of (23) yields to the following relations between the coefficient $B_{0}^{i}$ defined in (10) and (11)

$$
\sum_{i=1}^{Q} B_{0}^{i}=0
$$

The flux density distribution in the inner air-gap can be deduced from the magnetic vector potential by

$$
\begin{aligned}
& B_{I I r}=\frac{1}{r} \frac{\partial A_{I I}}{\partial \theta} \\
& B_{I I \theta}=-\frac{\partial A_{I I}}{\partial r}
\end{aligned}
$$

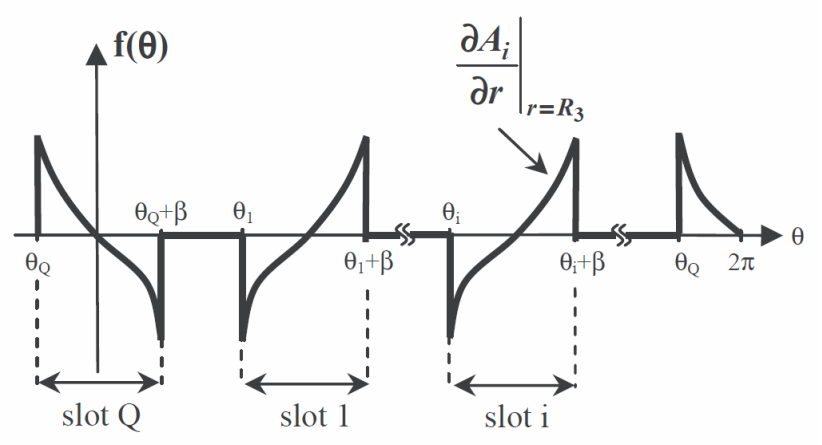

Fig. 4. Schematic representation of $f(\theta)$ along the inner air-gap at $r=R_{3}$.

The radial and the tangential components of the magnetic flux in the inner air-gap are then

$B_{I I r}(r, \theta)=$

$+\sum_{n=1}^{\infty}-\left(A_{n}^{I I} \frac{R_{2}}{r} \frac{P_{n}\left(r, R_{3}\right)}{E_{n}\left(R_{2}, R_{3}\right)}+B_{n}^{I I} \frac{R_{3}}{r} \frac{P_{n}\left(r, R_{2}\right)}{E_{n}\left(R_{3}, R_{2}\right)}\right) \sin (n \theta)$

$+\sum_{n=1}^{\infty}\left(C_{n}^{I I} \frac{R_{2}}{r} \frac{P_{n}\left(r, R_{3}\right)}{E_{n}\left(R_{2}, R_{3}\right)}+D_{n}^{I I} \frac{R_{3}}{r} \frac{P_{n}\left(r, R_{2}\right)}{E_{n}\left(R_{3}, R_{2}\right)}\right) \cos (n \theta)$

$B_{I I \theta}(r, \theta)=$

$+\sum_{n=1}^{\infty}-\left(A_{n}^{I I} \frac{R_{2}}{r} \frac{E_{n}\left(r, R_{3}\right)}{E_{n}\left(R_{2}, R_{3}\right)}+B_{n}^{I I} \frac{R_{3}}{r} \frac{E_{n}\left(r, R_{2}\right)}{E_{n}\left(R_{3}, R_{2}\right)}\right) \cos (n \theta)$

$+\sum_{n=1}^{\infty}-\left(C_{n}^{I I} \frac{R_{2}}{r} \frac{E_{n}\left(r, R_{3}\right)}{E_{n}\left(R_{2}, R_{3}\right)}+D_{n}^{I I} \frac{R_{3}}{r} \frac{E_{n}\left(r, R_{2}\right)}{E_{n}\left(R_{3}, R_{2}\right)}\right) \sin (n \theta)$

\section{2) Outer air-gap sub-domain (region III)}

The outer air-gap sub-domain and the associated boundary conditions are shown in Fig. 5. The problem to solve is

$\frac{\partial^{2} A_{I I I}}{\partial r^{2}}+\frac{1}{r} \frac{\partial A_{I I I}}{\partial r}+\frac{1}{r^{2}} \frac{\partial^{2} A_{I I I}}{\partial \theta^{2}}=0 \quad$ for $\quad\left\{\begin{array}{l}R_{4} \leq r \leq R_{5} \\ 0 \leq \theta \leq 2 \pi\end{array}\right.$

The boundary condition for the outer air-gap domain at $r=R_{5}$ is

$\left.\frac{\partial A_{I I I}}{\partial r}\right|_{r=R_{5}}=\left.\frac{\partial A_{I V}}{\partial r}\right|_{r=R_{5}}$

The boundary condition at the radius $r=R_{4}$ can be written as

$\left.\frac{\partial A_{I I I}}{\partial r}\right|_{r=R_{4}}=g(\theta)$ 


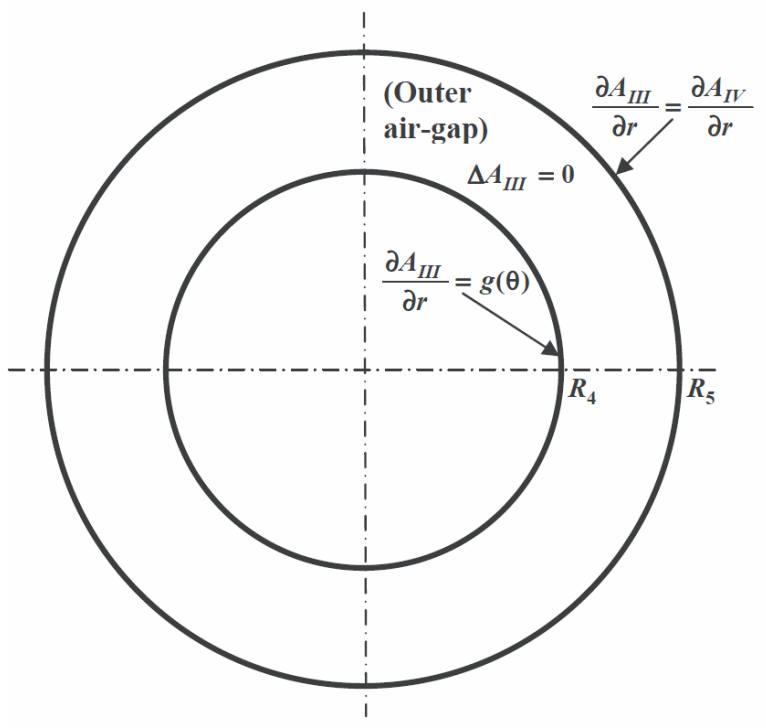

Fig. 5. Outer air-gap sub-domain (region III) with its boundary conditions. with

$g(\theta)= \begin{cases}\left.\frac{\partial A_{i}}{\partial r}\right|_{r=R_{4}} & \forall \theta \in\left[\theta_{i}, \theta_{i}+\beta\right] \\ 0 & \text { elsewhere }\end{cases}$

By taking into account the boundary conditions (30) and (31), the general solution of the magnetic vector potential in the outer air-gap sub-domain can be written as

$$
\begin{aligned}
& A_{I I I}(r, \theta)=A_{0}^{I I I} \\
& +\sum_{n=1}^{\infty}\left(A_{n}^{I I I} \frac{R_{4}}{n} \frac{P_{n}\left(r, R_{5}\right)}{E_{n}\left(R_{4}, R_{5}\right)}+B_{n}^{I I I} \frac{R_{5}}{n} \frac{P_{n}\left(r, R_{4}\right)}{E_{n}\left(R_{5}, R_{4}\right)}\right) \cos (n \theta) \\
& +\sum_{n=1}^{\infty}\left(C_{n}^{I I I} \frac{R_{4}}{n} \frac{P_{n}\left(r, R_{5}\right)}{E_{n}\left(R_{4}, R_{5}\right)}+D_{n}^{I I I} \frac{R_{5}}{n} \frac{P_{n}\left(r, R_{4}\right)}{E_{n}\left(R_{4}, R_{5}\right)}\right) \sin (n \theta)
\end{aligned}
$$

where $n$ is a positive integer, $P_{n}\left(r, R_{5}\right)$ and $E_{n}\left(R_{4}, R_{5}\right)$ are defined by (2) and (3). The coefficients $A_{n}^{I I I}, B_{n}^{I I I}, C_{n}^{I I I}$ and $D_{n}^{I I I}$ are determined using a Fourier series expansions of $\left.\frac{\partial A_{I V}}{\partial r}\right|_{R_{5}}$ and $g(\theta)$ over the air-gap interval $[0,2 \pi]$

$$
\begin{aligned}
& A_{n}^{I I I}=\frac{2}{2 \pi} \int_{0}^{2 \pi} g(\theta) \cdot \cos (n \theta) \cdot d \theta \\
& B_{n}^{I I I}=\left.\frac{2}{2 \pi} \int_{0}^{2 \pi} \frac{\partial A_{I V}}{\partial r}\right|_{r=R_{5}} \cdot \cos (n \theta) \cdot d \theta
\end{aligned}
$$

$$
\begin{aligned}
& C_{n}^{I I I}=\frac{2}{2 \pi} \int_{0}^{2 \pi} g(\theta) \cdot \sin (n \theta) \cdot d \theta \\
& D_{n}^{I I I}=\left.\frac{2}{2 \pi} \int_{0}^{2 \pi} \frac{\partial A_{I V}}{\partial r}\right|_{R_{5}} \cdot \sin (n \theta) \cdot d \theta
\end{aligned}
$$

The expressions for the coefficients $A_{n}^{I I I}, B_{n}^{I I I}, C_{n}^{I I I}$ and $D_{n}^{I I I}$ are given in the appendix.

C. General solution of Poisson's equation in the PMs subdomains (regions I and IV)

\section{1) Inner rotor PMs sub-domain (region I)}

The inner rotor PMs sub-domain and the associated boundary conditions are shown in Fig. 6. The problem to solve is

$$
\frac{\partial^{2} A_{I}}{\partial r^{2}}+\frac{1}{r} \frac{\partial A_{I}}{\partial r}+\frac{1}{r^{2}} \frac{\partial^{2} A_{I}}{\partial \theta^{2}}=\frac{\mu_{0}}{r} \frac{\partial M_{r}}{\partial \theta} \text { for }\left\{\begin{array}{l}
R_{1} \leq r \leq R_{2} \\
0 \leq \theta \leq 2 \pi
\end{array}\right.
$$

where $\mu_{0}$ is the permeability of the vacuum and $M_{r}$ is the radial magnetization of the magnets.

The boundary conditions at $r=R_{1}$ and $r=R_{2}$ are respectively

$\left.\frac{\partial A_{I}}{\partial r}\right|_{r=R_{1}}=0$

$A_{I}\left(R_{2}, \theta\right)=A_{I I}\left(R_{2}, \theta\right)$

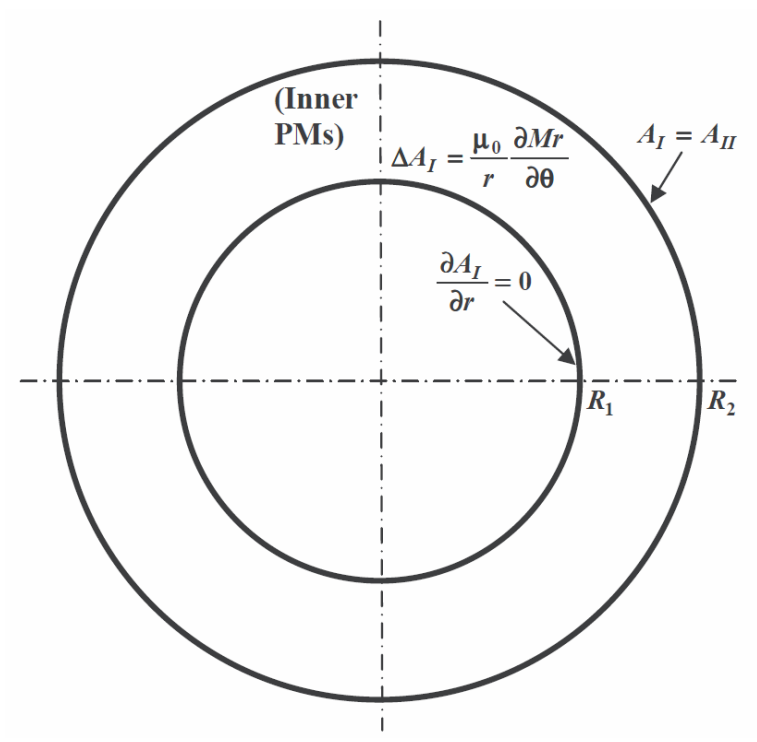

Fig. 6. Inner PMs sub-domain (region I) with its boundary conditions. 
The radial magnetization distribution $\mathrm{M}_{\mathrm{r}}$ is plotted in Fig. 7, where $B_{r}$ is the remanence of the magnets and $\varphi_{i}$ is the initial phase angle of the inner rotor. The radial magnetization can be expressed in Fourier's series and replaced in (38).

According to the superposition law, the general solution of (38) is the sum of the general solution of the corresponding Laplace's equation and a particular solution [15]. Taking into account the boundary conditions (39) and (40), the general solution of the magnetic vector potential in the inner PMs subdomain can be written as

$$
\begin{aligned}
& A_{I}(r, \theta)= \\
& +\sum_{n=1}^{\infty}\left(A_{n}^{I} \frac{P_{n}\left(r, R_{1}\right)}{P_{n}\left(R_{2}, R_{1}\right)}+X_{n}(r) \cos \left(n \varphi_{i}\right)\right) \cos (n \theta) \\
& +\sum_{n=1}^{\infty}\left(C_{n}^{I} \frac{P_{n}\left(r, R_{1}\right)}{P_{n}\left(R_{2}, R_{1}\right)}+X_{n}(r) \sin \left(n \varphi_{i}\right)\right) \sin (n \theta)
\end{aligned}
$$

where

$$
\begin{aligned}
X_{n}(r)=\left(1+\frac{1}{n}\left(\frac{R_{1}}{r}\right)^{n+1}\right) \cdot f_{n}(r) & \\
& \quad-\frac{P_{n}\left(r, R_{1}\right)}{P_{n}\left(R_{2}, R_{1}\right)}\left(1+\frac{1}{n}\left(\frac{R_{1}}{R_{2}}\right)^{n+1}\right) \cdot f_{n}\left(R_{2}\right)
\end{aligned}
$$

and

$$
f_{n}(r)= \begin{cases}\frac{4 . B_{r} \cdot r \cdot p_{i}}{\pi\left(1-n^{2}\right)} & \text { if } n=j p_{i} \text { with } j=1,3,5, \ldots . \\ \frac{2 \cdot B_{r}}{\pi} r \ln r & \text { if } n=p_{i}=1 \\ 0 & \text { otherwise }\end{cases}
$$

where $n$ is a positive integer, $p_{i}$ is the number of pole-pairs of the inner rotor and $P_{n}\left(r, R_{1}\right)$ is defined by (2).

The coefficients $A_{n}^{I}$ and $C_{n}^{I}$ are determined using a Fourier series expansion of $A_{I I}\left(R_{2}, \theta\right)$ over the interval $[0,2 \pi]$

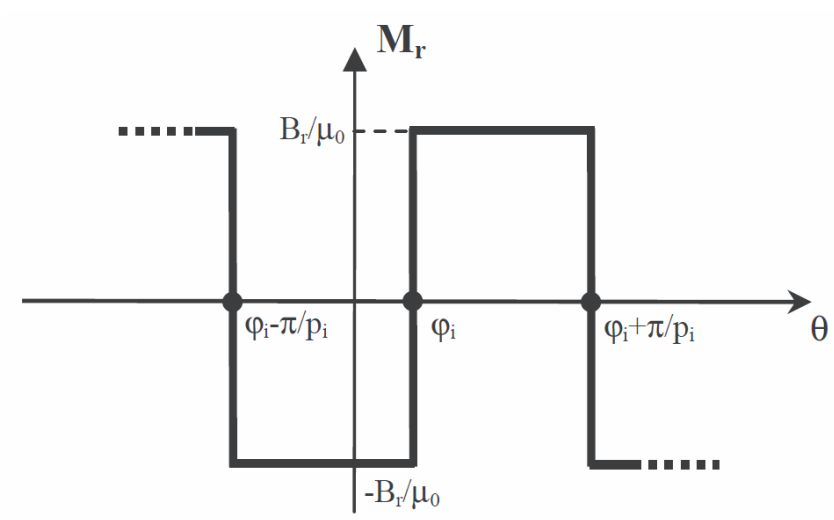

Fig. 7. Magnetization distribution along $\theta$-direction (inner PMs)

$$
\begin{aligned}
& A_{n}^{I}=\frac{2}{2 \pi} \int_{0}^{2 \pi} A_{I I}\left(R_{2}, \theta\right) \cdot \cos (n \theta) \cdot d \theta \\
& C_{n}^{I}=\frac{2}{2 \pi} \int_{0}^{2 \pi} A_{I I}\left(R_{2}, \theta\right) \cdot \sin (n \theta) \cdot d \theta
\end{aligned}
$$

The expressions for the coefficients $A_{n}^{I}$ and $C_{n}^{I}$ are given in the appendix.

2) Outer PMs sub-domain (region IV)

The outer PMs sub-domain and the associated boundary conditions are shown in Fig. 8. The problem to solve is

$\frac{\partial^{2} A_{I V}}{\partial r^{2}}+\frac{1}{r} \frac{\partial A_{I V}}{\partial r}+\frac{1}{r^{2}} \frac{\partial^{2} A_{I V}}{\partial \theta^{2}}=\frac{\mu_{0}}{r} \frac{\partial M_{r}}{\partial \theta}$ for $\left\{\begin{array}{l}R_{5} \leq r \leq R_{6} \\ 0 \leq \theta \leq 2 \pi\end{array}\right.$

The boundary conditions at $r=R_{5}$ and $r=R_{6}$ are respectively

$A_{I V}\left(R_{5}, \theta\right)=A_{I I I}\left(R_{5}, \theta\right)$

$\left.\frac{\partial A_{I V}}{\partial r}\right|_{r=R_{6}}=0$

By taking into account the boundary conditions (47) and (48), the general solution of the magnetic vector potential in the outer PMs sub-domain can be written as

$$
\begin{aligned}
& A_{I V}(r, \theta)= \\
& +\sum_{n=1}^{\infty}\left(A_{n}^{I V} \frac{P_{n}\left(r, R_{6}\right)}{P_{n}\left(R_{5}, R_{6}\right)}+Y_{n}(r) \cos \left(n \varphi_{o}\right)\right) \cos (n \theta) \\
& +\sum_{n=1}^{\infty}\left(C_{n}^{I V} \frac{P_{n}\left(r, R_{6}\right)}{P_{n}\left(R_{5}, R_{6}\right)}+Y_{n}(r) \sin \left(n \varphi_{o}\right)\right) \sin (n \theta)
\end{aligned}
$$

where

$$
\begin{aligned}
Y_{n}(r)=\left(1+\frac{1}{n}\left(\frac{R_{6}}{r}\right)^{n+1}\right) \cdot g_{n}(r) & \\
& \quad-\frac{P_{n}\left(r, R_{6}\right)}{P_{n}\left(R_{5}, R_{6}\right)}\left(1+\frac{1}{n}\left(\frac{R_{6}}{R_{5}}\right)^{n+1}\right) \cdot g_{n}\left(R_{5}\right)
\end{aligned}
$$

and

$$
g_{n}(r)= \begin{cases}\frac{4 \cdot B_{r} \cdot r \cdot p_{o}}{\pi\left(1-n^{2}\right)} & \text { if } n=j p_{o} \text { with } j=1,3,5, \ldots . . \\ \frac{2 \cdot B_{r}}{\pi} r \ln r & \text { if } n=p_{o}=1 \\ 0 & \text { otherwise }\end{cases}
$$




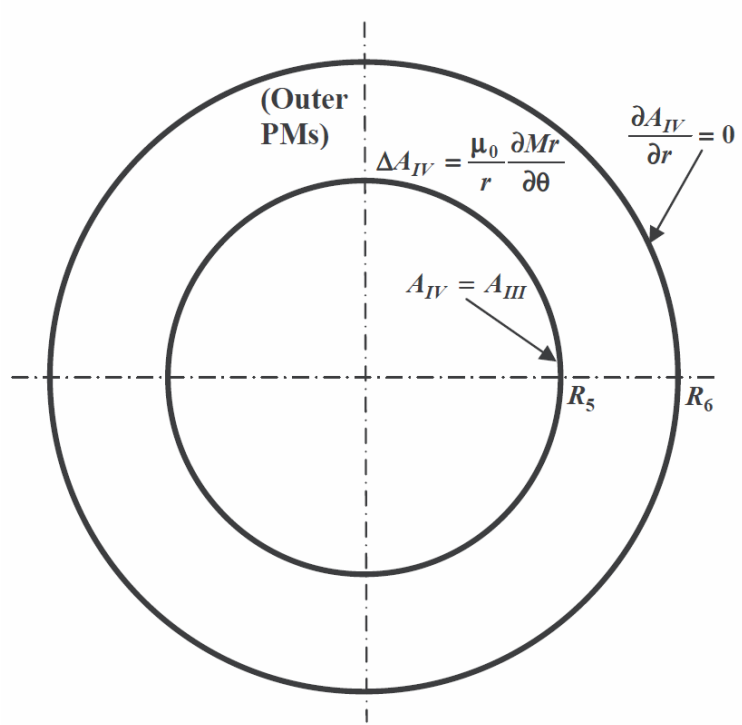

Fig. 8. Outer PMs sub-domain (region IV) with its boundary conditions.

where $n$ is a positive integer, $p_{o}$ is the number of pole-pairs of the outer rotor, $\varphi_{\mathrm{o}}$ is the initial phase angle of the outer rotor and $P_{n}\left(r, R_{6}\right)$ is defined by (2). The coefficients $A_{n}^{I V}$ and $C_{n}^{I V}$ are determined using a Fourier series expansion of $A_{I I I}\left(R_{5}, \theta\right)$ over the interval $[0,2 \pi]$

$$
\begin{aligned}
& A_{n}^{I V}=\frac{2}{2 \pi} \int_{0}^{2 \pi} A_{I I I}\left(R_{5}, \theta\right) \cdot \cos (n \theta) \cdot d \theta \\
& C_{n}^{I V}=\frac{2}{2 \pi} \int_{0}^{2 \pi} A_{I I I}\left(R_{5}, \theta\right) \cdot \sin (n \theta) \cdot d \theta
\end{aligned}
$$

The expressions for the coefficients $A_{n}^{I V}$ and $C_{n}^{I V}$ are given in the appendix.

\section{Electromagnetic torque}

The electromagnetic torque is obtained using the Maxwell stress tensor. A circle of radius $\mathrm{R}_{\mathrm{e}}$ in the inner air-gap subdomain is taken as the integration path so the electromagnetic torque is expressed as follows

$T_{e}=\frac{L R_{e}^{2}}{\mu_{0}} \int_{0}^{2 \pi} B_{I I r}\left(R_{e}, \theta\right) \cdot B_{I I \theta}\left(R_{e}, \theta\right) \cdot d \theta$

where $L$ is the axial length of the magnetic gear. According to (27) and (28), the analytical expression for the electromagnetic torque becomes

$$
T_{e}=\frac{\pi L R_{e}^{2}}{\mu_{0}} \sum_{n=1}^{\infty}\left(W_{n} X_{n}+Y_{n} Z_{n}\right)
$$

where

$$
\begin{gathered}
W_{n}=-A_{n}^{I I} \frac{R_{2}}{R_{e}} \frac{P_{n}\left(R_{e}, R_{3}\right)}{E_{n}\left(R_{2}, R_{3}\right)}-B_{n}^{I I} \frac{R_{3}}{R_{e}} \frac{P_{n}\left(R_{e}, R_{2}\right)}{E_{n}\left(R_{3}, R_{2}\right)} \\
X_{n}=-C_{n}^{I I} \frac{R_{2}}{R_{e}} \frac{E_{n}\left(R_{e}, R_{3}\right)}{E_{n}\left(R_{2}, R_{3}\right)}-D_{n}^{I I} \frac{R_{3}}{R_{e}} \frac{E_{n}\left(R_{e}, R_{2}\right)}{E_{n}\left(R_{3}, R_{2}\right)} \\
Y_{n}=C_{n}^{I I} \frac{R_{2}}{R_{e}} \frac{P_{n}\left(R_{e}, R_{3}\right)}{E_{n}\left(R_{2}, R_{3}\right)}+D_{n}^{I I} \frac{R_{3}}{R_{e}} \frac{P_{n}\left(R_{e}, R_{2}\right)}{E_{n}\left(R_{3}, R_{2}\right)} \\
Z_{n}=-A_{n}^{I I} \frac{R_{2}}{R_{e}} \frac{E_{n}\left(R_{e}, R_{3}\right)}{E_{n}\left(R_{2}, R_{3}\right)}-B_{n}^{I I} \frac{R_{3}}{R_{e}} \frac{E_{n}\left(R_{e}, R_{2}\right)}{E_{n}\left(R_{3}, R_{2}\right)}
\end{gathered}
$$

A similar expression can be obtained for the electromagnetic torque computation in the outer air-gap.

\section{APPLICATION EXAMPLE 1}

In order to validate the proposed model, the analytical results have been compared with $2 \mathrm{D}$ finite element simulations obtained using FEMM software [16]. In the finite-element analysis, the surfaces of the inner and outer rotors yokes as well as those of the ferromagnetic pole-pieces have been modeled by homogeneous Neumann boundary conditions as in the analytical study. The mesh in the air-gap and in the slot regions has been refined until convergent results are obtained.

The geometrical parameters given in Table I are considered in the simulation studies. The analytical solutions in the airgap, in the PMs and in the slots domains have been computed with a finite number of harmonic terms $N$ and $K$ as indicated in Table I.

\section{A. Flux density distribution}

Figure 9 shows the magnetic flux lines for the magnetic gear excited by both permanent magnet rotors. The phase angles $\varphi_{i}$ and $\varphi_{o}$ of the rotors PMs are fixed to zero. The corresponding flux density distributions (radial and tangential components) in the middle of the inner air-gap $(r=5.1 \mathrm{~cm})$ and in the middle of the outer air-gap $(r=6.3 \mathrm{~cm})$ are plotted respectively in Fig. 10 and Fig. 11. One can observe a very good agreement between the analytical and finite element predictions for both radial and tangential components.

TABLE I

PARAMETERS OF THE MODEL

\begin{tabular}{lll}
\hline \hline Symbol & \multicolumn{1}{c}{ Quantity } & \multicolumn{1}{c}{ value } \\
\hline$R_{1}$ & Radius of the inner rotor yoke & $4 \mathrm{~cm}$ \\
$R_{2}$ & Outer radius of the inner rotor PMs & $5 \mathrm{~cm}$ \\
$R_{3}$ & Inner radius of the slots & $5.2 \mathrm{~cm}$ \\
$R_{4}$ & Outer radius of the slots & $6.2 \mathrm{~cm}$ \\
$R_{5}$ & Inner radius of the outer rotor PMs & $6.4 \mathrm{~cm}$ \\
$R_{6}$ & Inner radius of the outer rotor yoke & $7.4 \mathrm{~cm}$ \\
$L$ & Axial length & $10 \mathrm{~cm}$ \\
$\beta$ & Slot opening & $\pi / 5 \mathrm{rad}$ \\
$B_{r}$ & Remanence of the magnets & $1.2 \mathrm{~T}$ \\
$p_{i}$ & Pole-pairs inner rotor & 2 \\
$p_{o}$ & Pole-pairs outer rotor & 3 \\
$Q$ & Number of ferromagnetic pole-pieces & 5 \\
$N$ & Number of harmonics used for magnetic field & 50 \\
& calculation in the air-gap and PMs domains & \\
$K$ & Number of harmonics used for magnetic field & 50 \\
\hline \hline
\end{tabular}




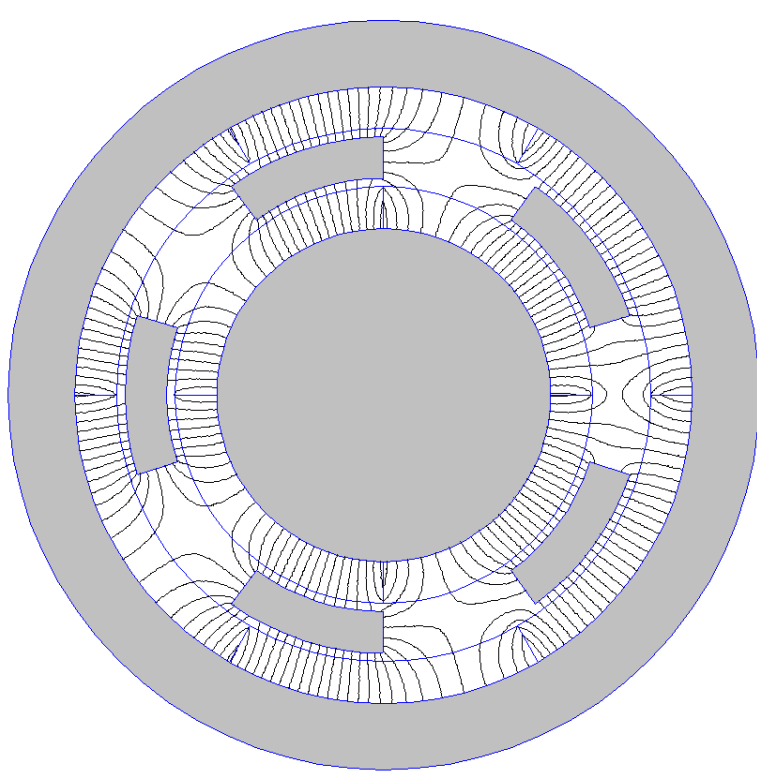

Fig. 9. Magnetic flux line distribution for the studied magnetic gear excited by both PMs rotors $\left(\varphi_{i}=0^{\circ}, \varphi_{0}=0^{\circ}\right.$ and $\left.\theta_{0}=0^{\circ}\right)$.

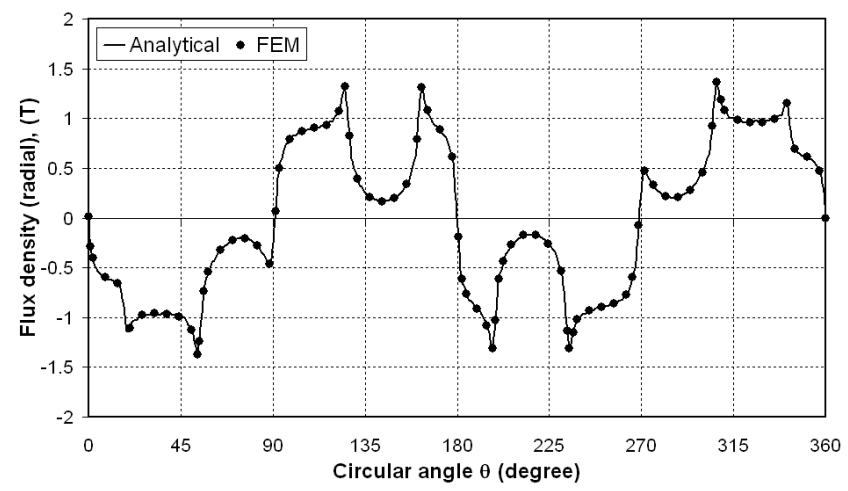

(a)

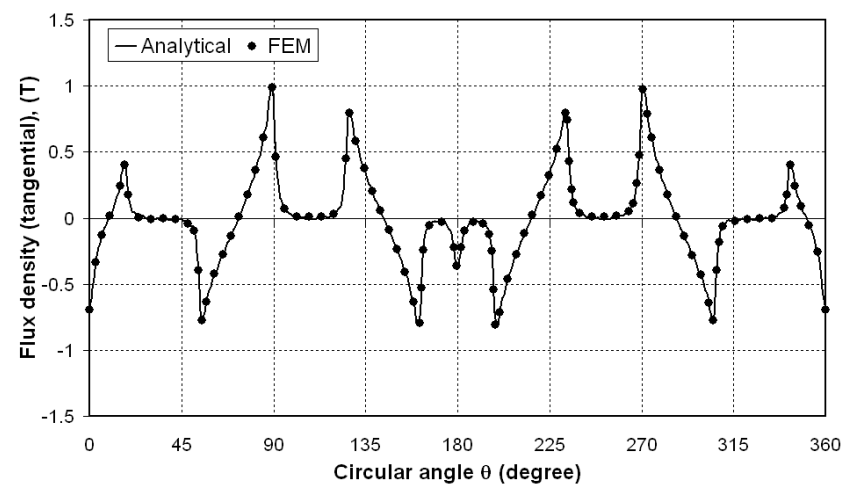

(b)

Fig. 10. Flux density distribution in the middle of the inner air-gap $(r=5$. $\mathrm{cm}$ ): (a) radial component (b) tangential component.

\section{B. Torque}

Figure 12 shows the variation of the torque which is exerted on the inner rotor while keeping the pole-pieces ring and the outer rotor fixed. The inner rotor rotates with a phase angle $\varphi_{\mathrm{i}}$ varying from $0^{\circ}$ to $90^{\circ}$. The analytical results are in good agreement with those obtained by the FEM. Fig. 12 shows that a maximum torque of $75 \mathrm{Nm}$ is obtained for a value of $\varphi_{i}$ around $51^{\circ}$.

Figures 13(a) and 13(b) show the variation of the electromagnetic torque which is exerted respectively on the inner and outer rotors. The pole-pieces ring is fixed while the inner and outer rotors PMs rotate in opposite direction as

$\varphi_{o}=-\varphi_{i} \cdot \frac{p_{i}}{p_{o}}$

The starting point for the phase angle of the inner rotor PMs is fixed at $\varphi_{i}=40^{\circ}$ that corresponds to a torque value exerted on the inner rotor of $61 \mathrm{Nm}$ (see Fig. 12). From Figs. 13(a) and 13(b), one can observe as expected that the magnetic gear amplifies the mean torque value by the gear ratio of $3 / 2$.

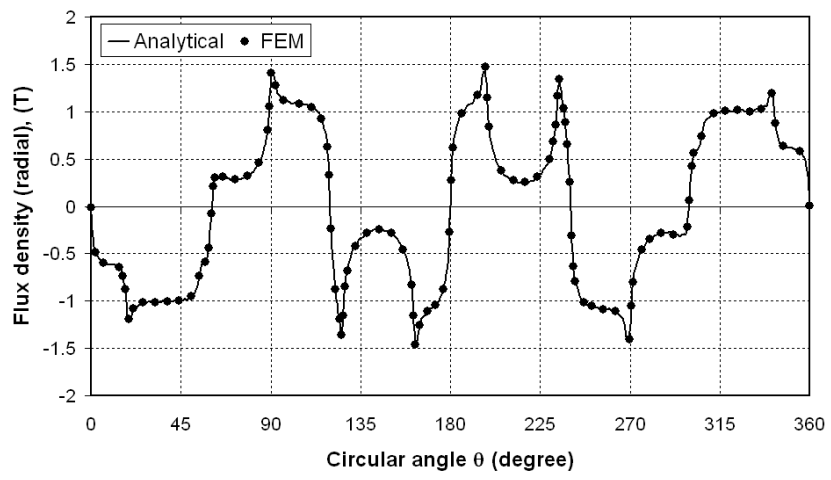

(a)

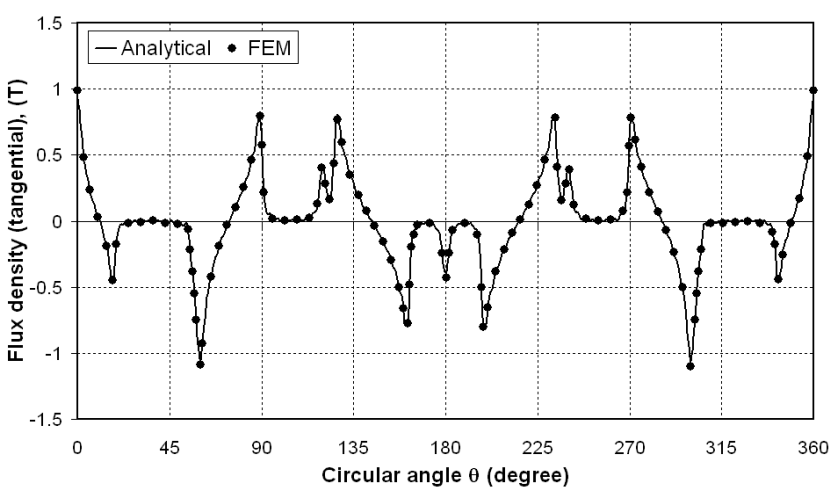

(b)

Fig. 11. Flux density distribution in the middle of the outer air-gap ( $r=6.3$ $\mathrm{cm}$ ): (a) radial component (b) tangential component. 
As shown in Figs. 13, the torque ripples are important in the studied example. Indeed, the low order harmonics are present in the flux density waveform of both air-gaps. This results in a low filtering of the air-gaps which leads to high pulsating torques. This effect can obviously be avoided by properly choosing $p_{o}$ and $Q$ for a given gear ratio [1]. Once again, very good agreement is obtained between numerical and analytical results.

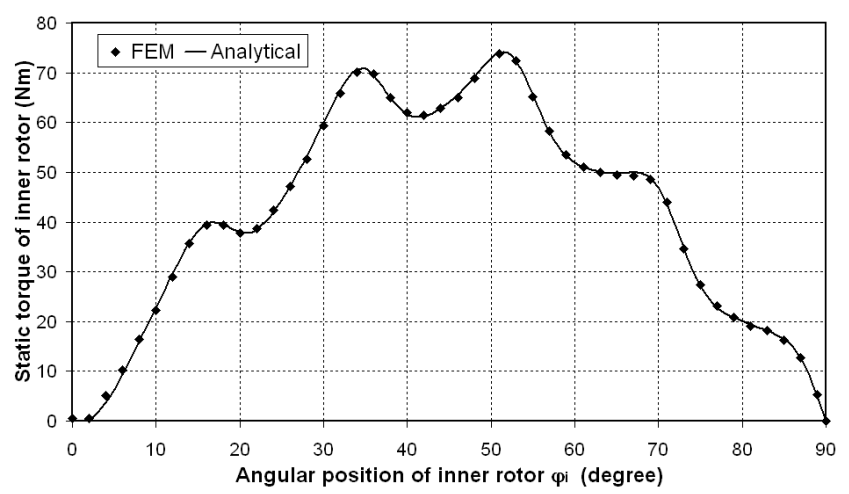

Fig. 12. Torque exerted on the inner rotor with the pole-pieces ring and the outer rotor fixed $\left(\varphi_{o}=0\right.$ and $\left.\theta_{0}=0\right)$.

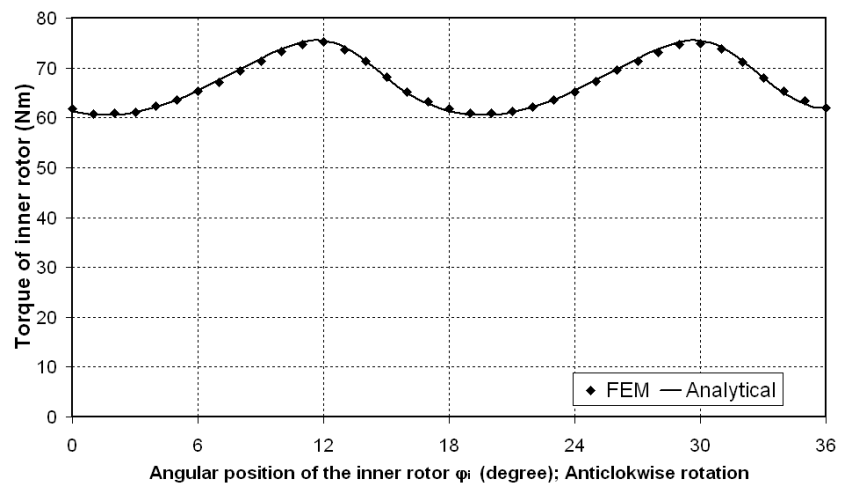

(a)

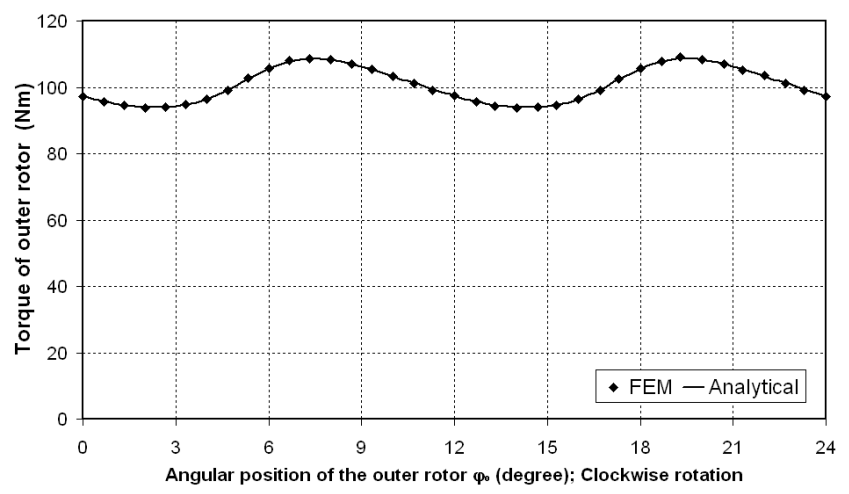

(b)

Fig. 13. Electromagnetic torque exerted on the inner rotor (a), and on the outer rotor $(b)$.

\section{APPLICATION EXAMPLE 2}

Another example is considered in this section. The same geometrical parameters as in Table I are used except for the pole-pair numbers which are now $p_{o}=3, p_{i}=13, Q=16$ which leads to a gear ratio equal to 4.33 .

The magnetic flux lines distribution for this configuration are shown in Fig. 14 (the slot opening is fixed to $\beta=\pi / 16$ ). The radial and tangential flux densities on a circle of the inner and outer air gaps are given in Fig. 15 and Fig. 16. A good agreement is noticed between the analytical and the numerical computations.

Figure 17 shows the static torque vs. position of the inner rotor. Compared to the configuration given in the first design example, the maximum torque is lower. However, the transmitted torque on the outer rotor is more important for the second example. Indeed, the gear ratio is more important for this configuration (4.33 instead of 1.5).

Furthermore, the torque ripples are practically inexistent for example 2 as it can be observed in Fig. 18. This confirms the influence of the pole-pairs combination on the torque pulsations [1].

To show the influence of the slot opening, Fig. 19 gives the variation of the electromagnetic torque exerted on the inner rotor against the "slot opening to tooth pitch" ratio. One can observe that the maximum torque is obtained for a ratio of 0.5 .

Again, we notice a close agreement between the analytical and numerical simulations.

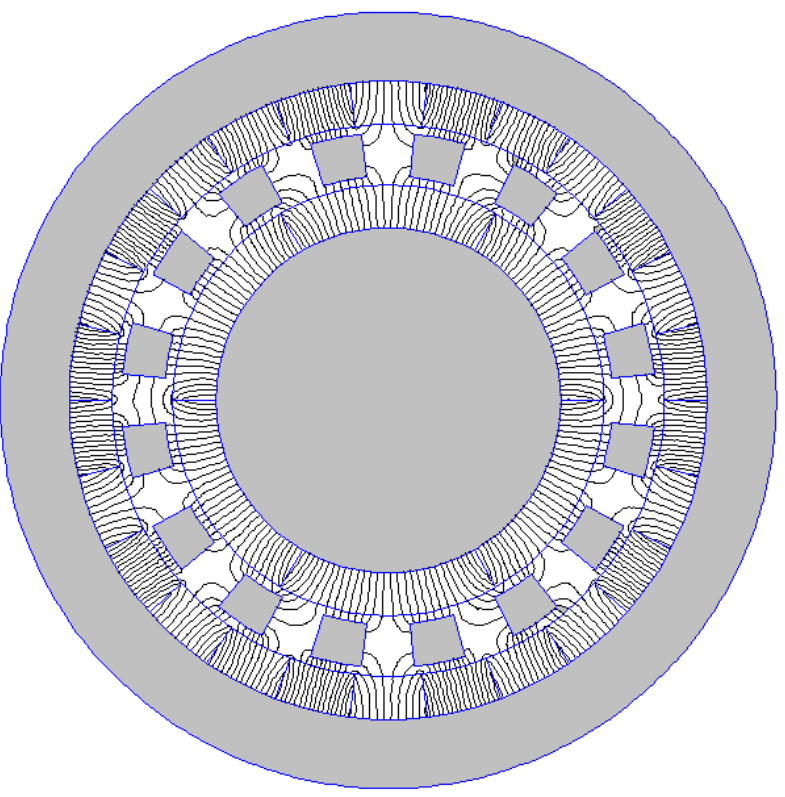

Fig. 14. Magnetic flux line distribution for the magnetic gear excited by both PMs rotors $\left(\varphi_{i}=0^{\circ}, \varphi_{0}=0^{\circ}\right.$ and $\left.\theta_{0}=0^{\circ}\right)$ 


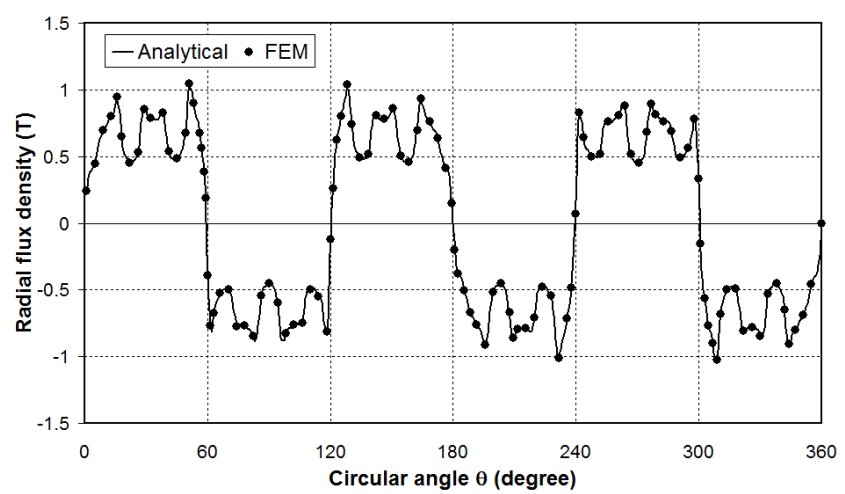

(a)

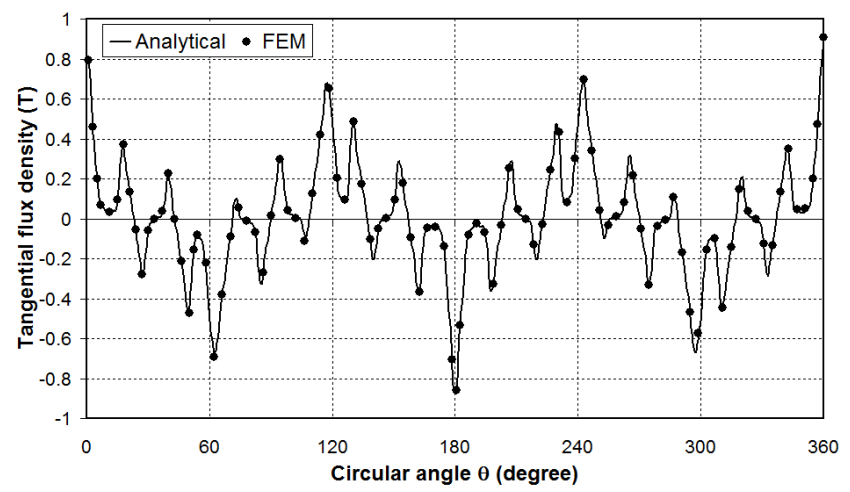

(b)

Fig. 15. Flux density distribution in the middle of the inner air-gap $(r=5.1$ $\mathrm{cm}$ ): (a) radial component (b) tangential component.

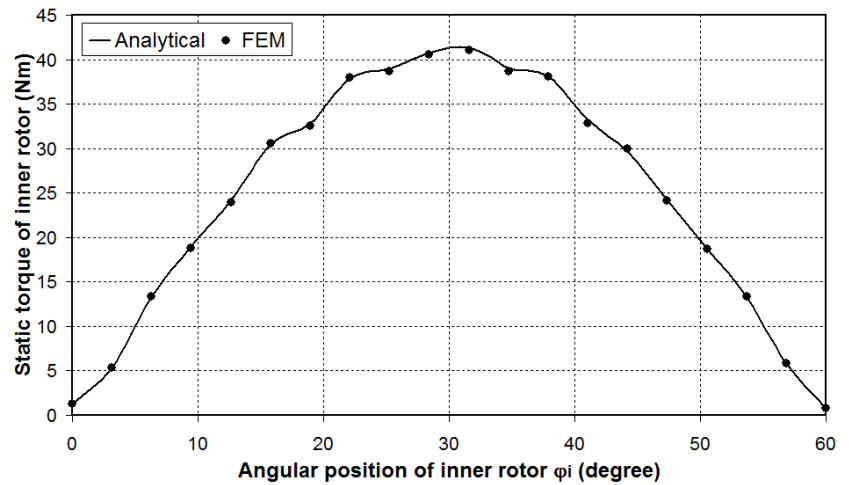

Fig. 17. Torque exerted on the inner rotor with the pole-pieces ring and the outer rotor fixed $\left(\varphi_{0}=0\right.$ and $\left.\theta_{0}=0\right)$

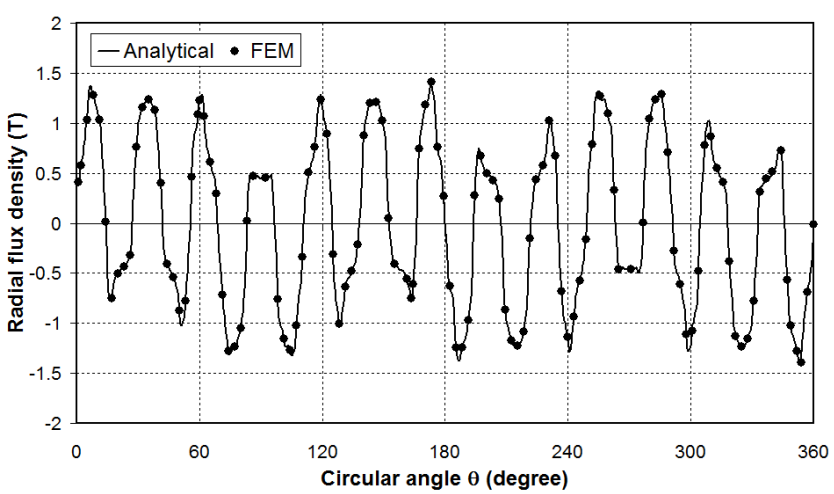

(a)

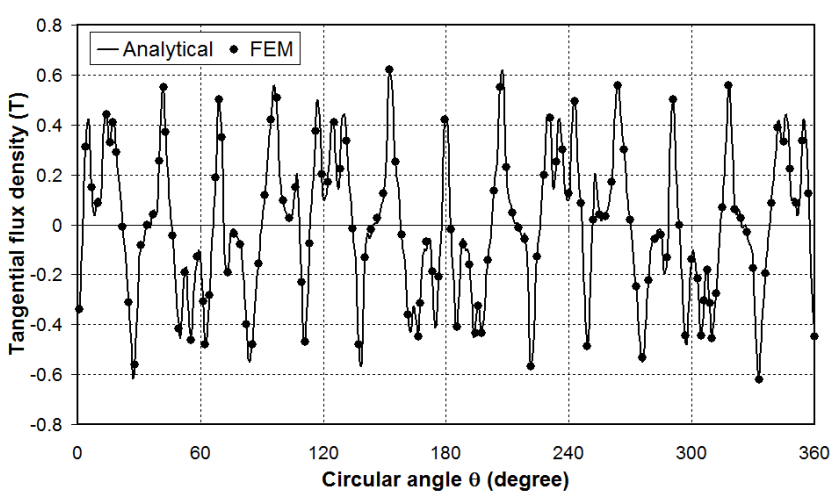

(b)

Fig. 16. Flux density distribution in the middle of the outer air-gap $(r=6.3$ $\mathrm{cm})$ : (a) radial component (b) tangential component.

\section{CONCLUSION}

In this paper, an exact 2-dimensional analytical method for predicting the magnetic field distribution in a magnetic gear has been presented. The Laplace's and Poisson's equations in polar coordinates have been solved by the technique of separation of variables in the slots, air-gap and PMs subdomains. The solutions have been obtained using boundary and continuity conditions between the sub-domains. Flux density and torque computations are in close agreement with these of FE predictions. The proposed analytical model presents lower computational time than FEM. Hence, it will be used in future work as a tool for design optimization of a magnetic gear. 


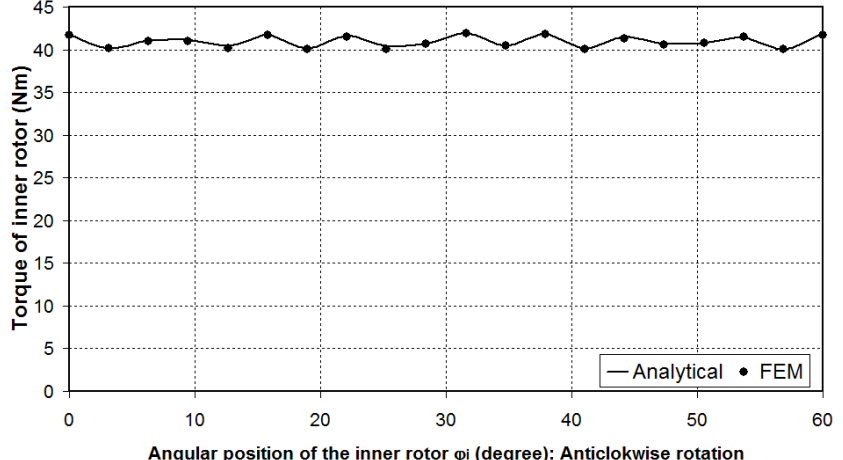

(a)

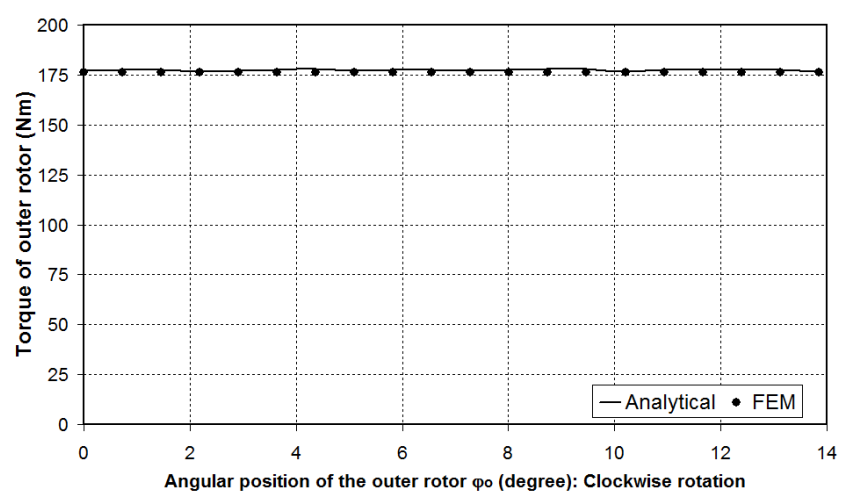

(b)

Fig. 18. Electromagnetic torque exerted on the inner rotor (a), and on the outer rotor (b).

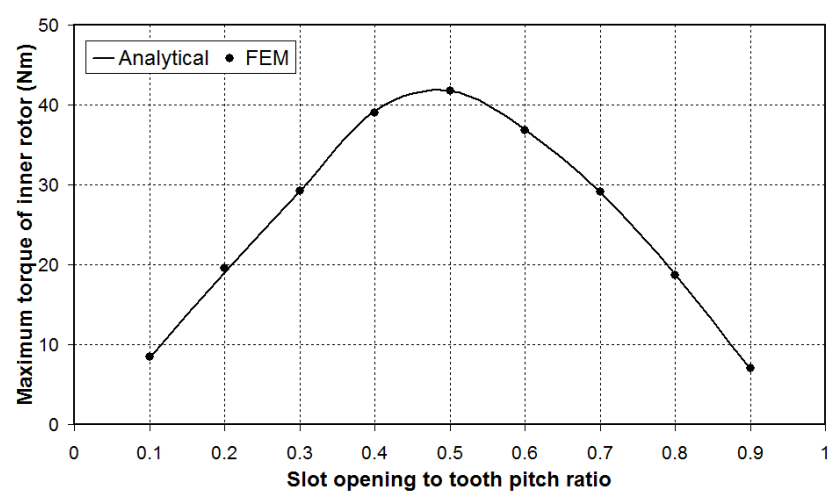

Fig. 19. Maximal torque on the inner rotor vs. "slot opening to tooth pitch" ratio.

\section{APPENDIX}

For the determination of the integration coefficients, we have to calculate integrals of the form

$$
\begin{aligned}
& f(k, n, i)=\int_{\theta_{i}}^{\theta_{i}+\beta} \cos (n \theta) \cdot \cos \left(\frac{k \pi}{\beta}\left(\theta-\theta_{i}\right)\right) \cdot d \theta \\
& g(k, n, i)=\int_{\theta_{i}}^{\theta_{i}+\beta} \sin (n \theta) \cdot \cos \left(\frac{k \pi}{\beta}\left(\theta-\theta_{i}\right)\right) \cdot d \theta \\
& r(n, i)=\int_{\theta_{i}}^{\theta_{i}+\beta} \cos (n \theta) \cdot d \theta \\
& s(n, i)=\int_{\theta_{i}}^{\theta_{i}+\beta} \sin (n \theta) \cdot d \theta
\end{aligned}
$$

The development of (A.1) and (A.2) gives the following functions that will be used in the expressions of the integration coefficients

- for $k \pi \neq n \beta$

$f(k, n, i)=\frac{-n \beta^{2}\left((-1)^{k} \sin n\left(\beta+\theta_{i}\right)-\sin \left(n \theta_{i}\right)\right)}{k^{2} \pi^{2}-n^{2} \beta^{2}}$

$g(k, n, i)=\frac{n \beta^{2}\left((-1)^{k} \cos n\left(\beta+\theta_{i}\right)-\cos \left(n \theta_{i}\right)\right)}{k^{2} \pi^{2}-n^{2} \beta^{2}}$

- for $k \pi=n \beta$

$$
\begin{aligned}
& f(k, n, i)=\frac{\beta}{2}\left(\cos \left(n \theta_{i}\right)+\frac{1}{2 k \pi}\left(\sin n\left(\theta_{i}+2 \beta\right)-\sin \left(n \theta_{i}\right)\right)\right) \\
& g(k, n, i)=\frac{\beta}{2}\left(\sin \left(n \theta_{i}\right)-\frac{1}{2 k \pi}\left(\cos n\left(\theta_{i}+2 \beta\right)-\cos \left(n \theta_{i}\right)\right)\right)
\end{aligned}
$$

The development of (A.3) and (A.4) gives the following functions

$r(n, i)=\frac{1}{n}\left(\sin \left(n \theta_{i}+n \beta\right)-\sin \left(n \theta_{i}\right)\right)$

$s(n, i)=\frac{1}{n}\left(-\cos \left(n \theta_{i}+n \beta\right)+\cos \left(n \theta_{i}\right)\right)$

- Expressions of the coefficients $A_{n}^{I I}, B_{n}^{I I}, C_{n}^{I I}$ and $D_{n}^{I I}$ for the inner air-gap sub-domain

The development of (19) and (21) gives 
$A_{n}^{I I}=A_{n}^{I} \frac{n}{R_{2}} \frac{E_{n}\left(R_{2}, R_{1}\right)}{P_{n}\left(R_{2}, R_{1}\right)}+X_{n}^{\prime}\left(R_{2}\right) \cos \left(n \varphi_{i}\right)$

$C_{n}^{I I}=C_{n}^{I} \frac{n}{R_{2}} \frac{E_{n}\left(R_{2}, R_{1}\right)}{P_{n}\left(R_{2}, R_{1}\right)}+X_{n}^{\prime}\left(R_{2}\right) \sin \left(n \varphi_{i}\right)$

The coefficient $B_{n}^{I I}$ and $C_{n}^{I I}$ defined in (20) and (22) can be written as

$$
\begin{aligned}
& B_{n}^{I I}=\left.\frac{2}{2 \pi} \sum_{i=1}^{Q} \int_{\theta_{i}}^{\theta_{i}+\beta} \frac{\partial A_{i}}{\partial r}\right|_{r=R_{3}} \cdot \cos (n \theta) \cdot d \theta \\
& D_{n}^{I I}=\left.\frac{2}{2 \pi} \sum_{i=1}^{Q} \int_{\theta_{i}}^{\theta_{i}+\beta} \frac{\partial A_{i}}{\partial r}\right|_{r=R_{3}} \cdot \sin (n \theta) \cdot d \theta
\end{aligned}
$$

where $\mathrm{Q}$ is the number of rotor slots. The development of (A.13) and (A.14) gives

$$
\begin{aligned}
& B_{n}^{I I}=\sum_{i=1}^{Q} \frac{B_{0}^{i}}{\pi R_{3}} \cdot r(n, i) \\
& +\sum_{i=1}^{Q} \sum_{k=1}^{\infty} A_{k}^{i} \frac{k}{\beta R_{3}} \frac{P_{k \pi / \beta}\left(R_{3}, R_{4}\right)}{E_{k \pi / \beta}\left(R_{3}, R_{4}\right)} \cdot f(k, n, i) \\
& -\sum_{i=1}^{Q} \sum_{k=1}^{\infty} B_{k}^{i} \frac{k}{\beta R_{3}} \frac{2}{E_{k \pi / \beta}\left(R_{3}, R_{4}\right)} \cdot f(k, n, i) \\
& D_{n}^{I I}=\sum_{i=1}^{Q} \frac{B_{0}^{i}}{\pi R_{3}} \cdot s(n, i) \\
& +\sum_{i=1}^{Q} \sum_{k=1}^{\infty} A_{k}^{i} \frac{k}{\beta R_{3}} \frac{P_{k \pi / \beta}\left(R_{3}, R_{4}\right)}{E_{k \pi / \beta}\left(R_{3}, R_{4}\right)} \cdot g(k, n, i) \\
& -\sum_{i=1}^{Q} \sum_{k=1}^{\infty} B_{k}^{i} \frac{k}{\beta R_{3}} \frac{2}{E_{k \pi / \beta}\left(R_{3}, R_{4}\right)} \cdot g(k, n, i)
\end{aligned}
$$

- Expressions of the coefficients $A_{n}^{I I I}, B_{n}^{I I I}, C_{n}^{I I I}$ and $D_{n}^{I I I}$ for the outer air-gap sub-domain

The development of (35) and (37) gives

$$
\begin{aligned}
& B_{n}^{I I I}=A_{n}^{I V} \frac{n}{R_{5}} \frac{E_{n}\left(R_{5}, R_{6}\right)}{P_{n}\left(R_{5}, R_{6}\right)}+Y_{n}^{\prime}\left(R_{5}\right) \cos \left(n \varphi_{o}\right) \\
& D_{n}^{I I I}=C_{n}^{I V} \frac{n}{R_{5}} \frac{E_{n}\left(R_{5}, R_{6}\right)}{P_{n}\left(R_{5}, R_{6}\right)}+Y_{n}^{\prime}\left(R_{5}\right) \sin \left(n \varphi_{o}\right)
\end{aligned}
$$

The coefficient $B_{n}^{I I I}$ and $C_{n}^{I I I}$ defined in (34) and (35) can be written as

$$
\begin{aligned}
& A_{n}^{I I I}=\left.\frac{2}{2 \pi} \sum_{i=1}^{Q} \int_{\theta_{i}}^{\theta_{i}+\beta} \frac{\partial A_{i}}{\partial r}\right|_{r=R_{4}} \cdot \cos (n \theta) \cdot d \theta \\
& C_{n}^{I I I}=\left.\frac{2}{2 \pi} \sum_{i=1}^{Q} \int_{\theta_{i}}^{\theta_{i}+\beta} \frac{\partial A_{i}}{\partial r}\right|_{r=R_{4}} \cdot \sin (n \theta) \cdot d \theta
\end{aligned}
$$

where $\mathrm{Q}$ is the number of rotor slots. The development of (A.19) and (A.20) gives

$$
\begin{aligned}
& A_{n}^{I I I}=\sum_{i=1}^{Q} \frac{B_{0}^{i}}{\pi R_{4}} \cdot r(n, i) \\
& +\sum_{i=1}^{Q} \sum_{k=1}^{\infty} A_{k}^{i} \frac{k}{\beta R_{4}} \frac{2}{E_{k \pi / \beta}\left(R_{3}, R_{4}\right)} \cdot f(k, n, i)
\end{aligned}
$$

$-\sum_{i=1}^{Q} \sum_{k=1}^{\infty} B_{k}^{i} \frac{k}{\beta R_{4}} \frac{P_{k \pi / \beta}\left(R_{4}, R_{3}\right)}{E_{k \pi / \beta}\left(R_{3}, R_{4}\right)} \cdot f(k, n, i)$

$C_{n}^{I I I}=\sum_{i=1}^{Q} \frac{B_{0}^{i}}{\pi R_{4}} \cdot s(n, i)$

$+\sum_{i=1}^{Q} \sum_{k=1}^{\infty} A_{k}^{i} \frac{k}{\beta R_{4}} \frac{2}{E_{k \pi / \beta}\left(R_{3}, R_{4}\right)} \cdot g(k, n, i)$

$$
-\sum_{i=1}^{Q} \sum_{k=1}^{\infty} B_{k}^{i} \frac{k}{\beta R_{4}} \frac{P_{k \pi / \beta}\left(R_{4}, R_{3}\right)}{E_{k \pi / \beta}\left(R_{3}, R_{4}\right)} \cdot g(k, n, i)
$$

- Expressions of the coefficients $A_{n}^{I}$ and $C_{n}^{I}$, for the inner PMs sub-domain (44) and (45)

$$
\begin{aligned}
& A_{n}^{I}=A_{n}^{I I} \frac{R_{2}}{n} \frac{P_{n}\left(R_{2}, R_{3}\right)}{E_{n}\left(R_{2}, R_{3}\right)}+B_{n}^{I I} \frac{R_{3}}{n} \frac{2}{E_{n}\left(R_{3}, R_{2}\right)} \\
& C_{n}^{I}=C_{n}^{I I} \frac{R_{2}}{n} \frac{P_{n}\left(R_{2}, R_{3}\right)}{E_{n}\left(R_{2}, R_{3}\right)}+D_{n}^{I I} \frac{R_{3}}{n} \frac{2}{E_{n}\left(R_{3}, R_{2}\right)}
\end{aligned}
$$

- Expressions of the coefficients $A_{n}^{I V}$ and $C_{n}^{I V}$, for the outer PMs sub-domain (52) and (53)

$$
\begin{aligned}
& A_{n}^{I V}=A_{n}^{I I I} \frac{R_{4}}{n} \frac{2}{E_{n}\left(R_{4}, R_{5}\right)}+B_{n}^{I I I} \frac{R_{5}}{n} \frac{P_{n}\left(R_{5}, R_{4}\right)}{E_{n}\left(R_{5}, R_{4}\right)} \\
& C_{n}^{I V}=C_{n}^{I I I} \frac{R_{4}}{n} \frac{2}{E_{n}\left(R_{4}, R_{5}\right)}+D_{n}^{I I I} \frac{R_{5}}{n} \frac{P_{n}\left(R_{5}, R_{4}\right)}{E_{n}\left(R_{5}, R_{4}\right)}
\end{aligned}
$$

- Expression of the coefficients $A_{0}^{i}, B_{0}^{i}, A_{k}^{i}$ and $B_{k}^{i}$ for the $i$-th slot sub-domain

The treatment of (12) and (13) yields to the following linear relations 


$$
\begin{aligned}
& A_{k}^{i}=\sum_{n=1}^{\infty}\left(A_{n}^{I I} \frac{2 R_{2}}{n \beta} \frac{2}{E_{n}\left(R_{2}, R_{3}\right)}+B_{n}^{I I} \frac{2 R_{3}}{n \beta} \frac{P_{n}\left(R_{3}, R_{2}\right)}{E_{n}\left(R_{3}, R_{2}\right)}\right) \cdot f(k, n, i) \\
& +\sum_{n=1}^{\infty}\left(C_{n}^{I I} \frac{2 R_{2}}{n \beta} \frac{2}{E_{n}\left(R_{2}, R_{3}\right)}+D_{n}^{I I} \frac{2 R_{3}}{n \beta} \frac{P_{n}\left(R_{3}, R_{2}\right)}{E_{n}\left(R_{3}, R_{2}\right)}\right) \cdot g(k, n, i)
\end{aligned}
$$

$$
\begin{aligned}
& B_{k}^{i}=\sum_{n=1}^{\infty}\left(A_{n}^{I I I} \frac{2 R_{4}}{n \beta} \frac{P_{n}\left(R_{4}, R_{5}\right)}{E_{n}\left(R_{4}, R_{5}\right)}+B_{n}^{I I I} \frac{2 R_{5}}{n \beta} \frac{2}{E_{n}\left(R_{5}, R_{4}\right)}\right) \cdot f(k, n, i) \\
& +\sum_{n=1}^{\infty}\left(C_{n}^{I I I} \frac{2 R_{4}}{n \beta} \frac{P_{n}\left(R_{4}, R_{5}\right)}{E_{n}\left(R_{4}, R_{5}\right)}+D_{n}^{I I I} \frac{2 R_{5}}{n \beta} \frac{2}{E_{n}\left(R_{5}, R_{4}\right)}\right) \cdot g(k, n, i)
\end{aligned}
$$

The treatment of (10) and (11) yields to the following linear relations

$$
\begin{aligned}
& A_{0}^{i}+B_{0}^{i} \ln R_{3}=A_{0}^{I I} \\
& +\sum_{n=1}^{\infty}\left(A_{n}^{I I} \frac{R_{2}}{n \beta} \frac{2}{E_{n}\left(R_{2}, R_{3}\right)}+B_{n}^{I I} \frac{R_{3}}{n \beta} \frac{P_{n}\left(R_{3}, R_{2}\right)}{E_{n}\left(R_{3}, R_{2}\right)}\right) \cdot r(n, i) \\
& +\sum_{n=1}^{\infty}\left(C_{n}^{I I} \frac{R_{2}}{n \beta} \frac{2}{E_{n}\left(R_{2}, R_{3}\right)}+D_{n}^{I I} \frac{R_{3}}{n \beta} \frac{P_{n}\left(R_{3}, R_{2}\right)}{E_{n}\left(R_{3}, R_{2}\right)}\right) \cdot s(n, i) \\
& A_{0}^{i}+B_{0}^{i} \ln R_{4}=A_{0}^{I I I} \\
& +\sum_{n=1}^{\infty}\left(A_{n}^{I I I} \frac{R_{4}}{n \beta} \frac{P_{n}\left(R_{4}, R_{5}\right)}{E_{n}\left(R_{4}, R_{5}\right)}+B_{n}^{I I I} \frac{R_{5}}{n \beta} \frac{2}{E_{n}\left(R_{5}, R_{4}\right)}\right) \cdot r(n, i) \\
& +\sum_{n=1}^{\infty}\left(C_{n}^{I I I} \frac{R_{4}}{n \beta} \frac{P_{n}\left(R_{4}, R_{5}\right)}{E_{n}\left(R_{4}, R_{5}\right)}+D_{n}^{I I I} \frac{R_{5}}{n \beta} \frac{2}{E_{n}\left(R_{5}, R_{4}\right)}\right) \cdot s(n, i)
\end{aligned}
$$

We have to solve a system of linear equations with the same number of unknowns. By rewriting the above equations in matrix and vectors form, a numerical solution can be found by using mathematical software (Matlab or Maple).

\section{REFERENCES}

[1] K. Atallah and D. Howe, "A novel high-performance magnetic gear," IEEE Trans. Magn., vol. 37, no. 4, pp. 2844-2846, Jul. 2001.

[2] K. Atallah, S. Calverley and D. Howe, "Design, analysis and realization of a high-performance magnetic gear," IEE Proc. Electric Power Appl., vol. 151 , no. 2 , pp. 135-143, 2004

[3] S. Mezani, K. Atallah, and D. Howe, "A high-performance axial-field magnetic gear,” J. Appl. Phys., vol. 99, 08R303, 2006.

[4] P. O. Rasmussen, T. O. Andersen, F. T. Jorgensen, and O. Nielsen, "Development of a high-performance magnetic gear," IEEE Trans. Ind. Appl., vol. 41, no. 3, pp. 764-770, May/Jun. 2005.

[5] K. T. Chau, D. Zhang, J. Z. Jiang, and L. Jian, "Transient analysis of coaxial magnetic gears using finite element comodeling," J. Appl. Phys., vol. 103, 07F101, 2008

[6] K. Atallah, J. Rens, S. Mezani, D. Howe, "A Novel "pseudo" directdrive brushless permanent magnet machine," IEEE Transactions on Magnetics, Vol. 44, No. 11, November 2008, pp. 4349 - 4352.

[7] K. T. Chau, D. Zhang, J. Z. Jiang, C. Liu, and Y. Zhang, "Design of a magnetic-geared outer-rotor permanent-magnetic brushless motor for electric vehicles," IEEE Trans. Magn., vol. 43, no. 6, pp. 2504-2506, Jun. 2007.

[8] L. Jian, K. T. Chau, and J. Z. Jiang, "A magnetic-geared outer-rotor permanent-magnet brushless machine for wind power generation," IEEE Trans. Ind. Appl., vol. 35, no. 3, pp. 954-92, May/Jun. 2009.

[9] B. Ackermann and R. Sottek, "Analytical modeling of the cogging torque in permanent magnet motors," Elect. Eng., vol. 78, no. 2, pp. 117-125, Mar. 1994.

[10] Z. Q. Zhu and D. Howe, "Instantaneous magnetic-field distribution in brushless permanent-magnet dc motor, part III: Effect of slotting," IEEE Trans. Magn., vol. 29, no. 1, pp. 143-151, Jan. 1993.

[11] D. Zarko, D. Ban, and T. A. Lipo, "Analytical calculation of magnetic field distribution in the slotted air gap of a surface permanent-magnet motor using complex relative air-gap permeance," IEEE Trans. Magn., vol. 42, no. 7, pp. 1828-1837, Jul. 2006.

[12] Z. J. Liu, and J. T. Li, “Analytical solution of air-gap field in permanent magnet motors taking into account the effect of pole transition over slots," IEEE Trans. Magn., vol. 43, no. 10, pp. 3872-3882, Oct. 2007.

[13] Z. J. Liu, and J. T. Li, "Accurate prediction of magnetic field and magnetic forces in permanent magnet motor using an analytical solution," IEEE Trans. Energy. Convers., vol. 23, no. 3, pp. 717-726, Sept. 2008.

[14] T. Lubin, S. Mezani, and A. Rezzoug, "Exact analytical method for magnetic field computation in the air-gap of cylindrical electrical machines considering slotting effects," IEEE Trans. Magn., accepted for publication.

[15] S. J. Farlow, Partial Differential Equations for Scientists and Engineers. Dover publications, New York, 414 pp, 1993.

[16] D. C. Meeker, "Finite Element Method Magnetics", Version 4.2 (1 April 2009 Build), http://www.femm.info.

Thierry Lubin was born in Sedan, France, in 1970. He received the M.S. Degree from the University of Paris 6, France in 1994 and the Ph.D. degree from the University Henri Poincaré, Nancy, France, in 2003.

$\mathrm{He}$ is currently a lecturer of Electrical Engineering at the University of Nancy at the Groupe de Recherche en Electrotechnique et Electronique de Nancy. His interests include modeling and control of electrical machine and applied superconductivity in electrical devices.

Smail Mezani was born in Algiers, Algeria, in 1974. He received the engineer diploma and the magister degree from the University of Sciences and Technology Houari Boumediene, Algiers, Algeria in 1996 and 1999 respectively. He obtained the Ph.D. degree from the Institut National Polytechnique de Lorraine, France, in 2004.

From 2004 to 2005, he was a Research Associate in the Department of Electronic and Electrical Engineering at the University of Sheffield, UK, where he worked on magnetic gears and "pseudo" direct drive electrical machines.

$\mathrm{He}$ is currently a lecturer at the University Henri Poincaré of Nancy, France, at the Groupe de Recherche en Electrotechnique et Electronique de Nancy where his research interests include the applications of superconductors in electromechanical devices.

Abderrezak Rezzoug received the Doctorat d'Etat from the Institut National Polytechnique de Lorraine, France, in 1987.

After working at the INPL as an assistant Professor until 1991, he joined the Université Henri Poincaré, Nancy, France, as a Professor. His interests are in superconducting applications to electrical devices, and the control and diagnosis of electrical machines. 